일반논문-11-16-4-02

$$
\begin{gathered}
\text { 컬러 및 깊이 데이터 변환을 이용하는 입체감 향상 } \\
\text { 길 종 인 }{ }^{a} \text {, 장 성 은 }{ }^{a)} \text {, 서 주 하 }{ }^{a)} \text {, 김 만 배 }{ }^{\text {a }}
\end{gathered}
$$

\title{
Stereoscopic Perception Improvement Using Color and Depth Transformation
}

\author{
Jong In Gil ${ }^{\text {a) }}$, Seung Eun Jang ${ }^{\text {a)}}$, Joo Ha Seo ${ }^{\text {a)}}$, and Man Bae $\mathrm{Kim}^{\text {a) }}{ }^{\ddagger}$ \\ 요 약
}

최근 RGB 영상과 깊이맵이 동시에 제작되어 공급되고 있다. 깊이맵은 사용자의 용도에 따라 다양한 형태로 변환되어 입체영상 제 작에 사용된다. 깊이맵을 활용하는 기법이 새로이 소개되고 있는데, 한 예로 의료 분야에서 2D 영상의 컬러를 변환하여 지각 깊이감 을 개선하는 영상처리 기술에 대한 관심이 높아지고 있다. 본 논문에서는 기존의 컬러 변환을 통한 2D 영상의 지각 깊이감 개선을 입 체영상에 적용하여, $3 \mathrm{D}$ 지각 깊이감을 동시에 향상시키는 방법을 제안한다. 이를 위해 대조 변환 및 배경 다크닝 방법을 제안하고, 실 험을 통해 제안 방법이 상기 목적을 얻을 수 있는 것을 검증하였다. 주관적 실험에서는 입체감 향상 및 피로도 측정을 통해 제안 방법 의 성능 및 단점을 제시하였다.

\section{Abstract}

Recently, RGB images and depth maps have been supplied to academic fields. The depth maps are utilized to the generation of stereoscopic images in the diverse formats according to the users' preference. A variety of methods that use depth maps have been introduced so far. One of applications is a medical field. In this area, the improvement of the perceptual quality of 2D medical images has gained much interest. In this paper, we propose a novel scheme that expands the conventional method to 3D stereoscopic image, thereby achieving the perceptual depth quality improvement as well as 3D stereoscopic perception enhancement at the same time. For this, contrast transformation as well as depth darkening are proposed and their performance is validated through the subjective test. Subjective experiments peformed for stereoscopic enhancement as well as visual fatigue validate that the proposed method achieves better 3D perception than the usage of the original stereoscopic image and suggests the limitation in terms of the visual fatigue.

Keywords : stereoscopic quality, contrast transformation, depth darkening, 3D enhancement

\section{I. 서 론}

a) 강원대학교 IT대학 컴퓨터정보통신공학과

Kangwon National Univ., Dept. of Computer \& Communications

‡ 교신저자 : 김만배 (manbae@kangwon.ac.kr)

※ 본 연구는 지식경제부 및 한국산업기술평가관리원의 IT산업원천기술개 발사업의 일환으로 수행하였음. [KI002058, 대화형 디지털 홀로그램 통 합서비스 시스템의 구현을 위한 신호처리 요소 기술 및 $\mathrm{SoC}$ 개발]

·접수일(2010년12월16일),수정일(1차:2011년4월21일,2차:6월21일),게재확정일(2 011년7월6일)
입체영상의 제작은 많은 분야에서 진행중이다. 기본적으 로 2개의 스테레오 카메라 센서 또는 입체 CG 기술로 입체 영상을 제작하는 것이 일반적인 방법이다. 다른 제작방법 은 $2 \mathrm{D}+\mathrm{Depth}$ 방법으로 $2 \mathrm{D}$ 영상과 깊이맵(depth map)을 이 용하여 입체영상을 제작하는 것이다. 후자는 전자와 달리, 
입체영상의 입체감 등을 자유롭게 조절할 수 있는 장점이 있어서, $2 \mathrm{D}$ 영상과 같이 깊이맵이 지속적으로 공급 및 이용 되고 있다. 이러한 깊이맵을 이용하여, $2 \mathrm{D}$ 영상의 지각 깊 이감 (perceived depth quality)을 향상시키는 연구가 꾸준 히 연구되고 있으며, 제안 방법은 상기 기술을 입체영상으 로 확대하여, 입체영상의 지각 입체감 (perceived stereoscopic quality)을 개선하는 것을 목적으로 한다.

예를 들어, $2 \mathrm{D}$ 영상의 컬러를 조절하여, 지각 깊이감을 향상시키는 영상처리 기술은 최근 들어 의료 영상 분야에서 특히 관심이 높아지고 있는 분야이다. 국부적으로 대조 (contrast)를 변경하여 깊이감이 다른 영상 개선 기법을 $\mathrm{CG}$ 에 도입하면서 시작되었는데, $2 \mathrm{D}$ 영상의 지각 깊이감의 개 선에 사용되었다. 여기서, 지각 깊이감은 영상 컬러값의 향

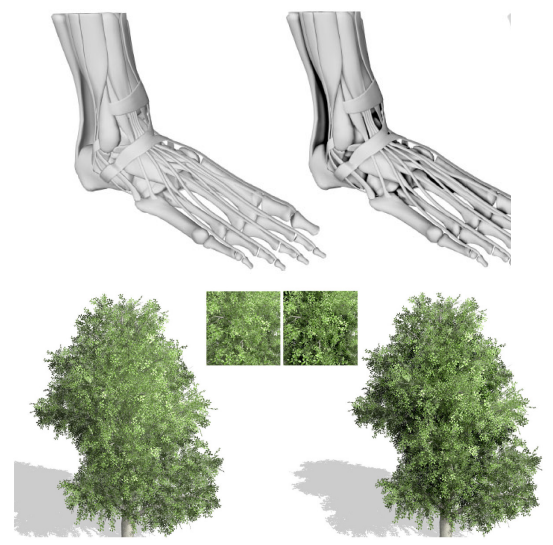

그림 1. 지각 깊이감이 개선된 영상의 예 [1]

Fig. 1. Examples of images with better perceived depth quality [1]
상 또는 저하가 아닌, 영상의 깊이감을 의미한다. 예를 들어, 그림 1 은 컬러의 대조를 변경하여 원영상보다 지각 깊이감 이 향상된 영상들을 보여준다. 실제 관찰해보면 우측 영상들 이 좌측의 원영상보다 깊이감이 향상되는 것을 알 수 있다.

그림 2는 $\mathrm{RGB}$ 영상의 지각 깊이감의 개선을 위한 기존 방법들의 기본 블록도를 보여준다. 입력으로 RGB 영상과 깊이맵이 있으면, 깊이맵에서 변환 정보를 구한다. 이 정보 를 활용하여, RGB 컬러를 변환하여 깊이감이 개선된 RGB 영상을 생성한다.

기존의 방법들은 RGB 컬러를 변환하기 위해 깊이맵에 서 필요한 변환 정보를 구하는데, 이 정보 획득 방법에 대한 연구가 대부분을 차지하고 있다. 최초 연구로 Luft 등은 깊 이맵에 언샤프 마스킹(unsharp masking)을 적용하여 얻은 변환정보를 이용하여 영상의 지각 깊이감을 향상시키는 기 법을 제안하였다 ${ }^{[1]}$. Svakhine은 [1]을 바탕으로 깊이 향상 기법을 제안하였다 ${ }^{[2]}$. 예를 들어 depth blending, depth cueing, depth blurring 등의 다양한 방법으로 영상을 개선하였 다. Bruckner 등은 후광 (halo) 효과를 3D 데이터로 확장하 여, 이를 구현하는 기법을 제안하였다 ${ }^{[3]}$. 상기 연구들은 $2 \mathrm{D}$ 영상에 국한되어 있으며, 주로 $\mathrm{CG}$ 의료영상을 실험영상으 로 사용하는 단점이 있다. 입체영상의 화질 및 입체감 개선 은 최근에 관심을 받고 있는 분야이다. Jung 등은 3 차원 색 상 보정용 사상표를 이용하여 얻은 입체영상의 화질이 기 존 방식보다 PSNR이 향상되는 것을 보였다 ${ }^{[4]}$. Kim 등은 깊이맵의 변이값을 재조정하여 $3 \mathrm{D}$ 입체감을 개선하는 다 시점영상처리 기법을 제안하였다 ${ }^{[5]}$. 본 논문은 [1-3]에서

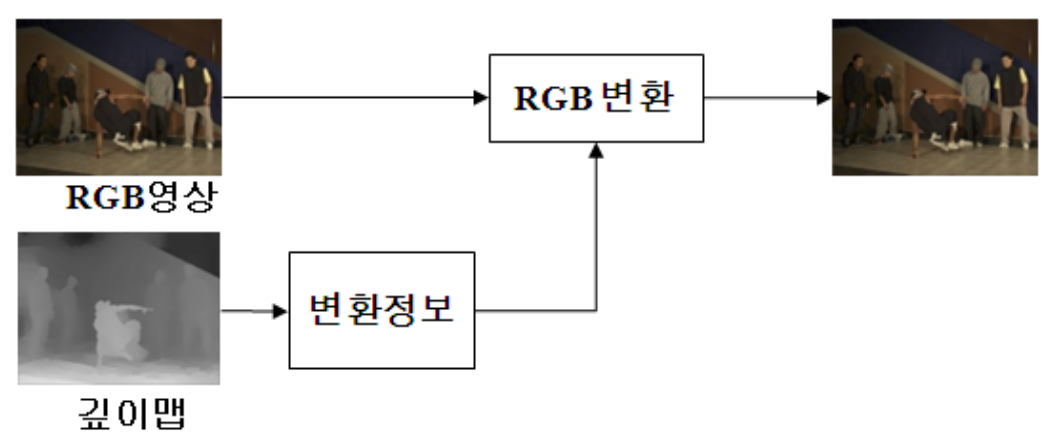

그림 2. RGB 영상의 지각 깊이감을 개선하는 기존 방법

Fig. 2. The conventional method of improving the perceived depth quality of RGB image 
제안한 방법을 $3 \mathrm{D}$ 입체영상 분야로 확장하고, 또한 실사영 상에 적용하여 입체효과의 개선을 얻고자 하는 것이 본 논 문의 목적이다. 또한 [5]는 변이(깊이)의 재조정으로 실제 인식하는 $3 \mathrm{D}$ 입체감을 향상시키는 것이나, 본 연구는 깊이 및 컬러값을 동시에 변환하여 입체감의 향상을 얻는다.

본 논문의 구성은 다음과 같다. 2장에서는 입체영상 개선 방법의 개요를 설명한다. 3 장에서는 RGB 컬러 변환 과정 을 설명하고, 이어서 4장은 깊이맵 변환 기법을 소개한다. 5 장의 실험에서는 얻어진 입체영상의 $3 \mathrm{D}$ 지각 입체감 향상 기법을 검증하고, 마지막으로 6장에서는 결론을 맺는다.

\section{II. 입체영상의 지각 입체감 개선}

그림 3은 입체영상의 지각 입체감을 개선하는 제안 방법 의 블록도이다. 기존 $2 \mathrm{D}$ 영상과 달리, 입체영상은 RGB 영 상 및 깊이맵의 두 데이터의 처리가 필요하다. RGB 영상은 지각 깊이감 개선을 위한 것이고, 깊이맵은 $3 \mathrm{D}$ 입체감을 높이는 데 사용된다. 본 논문에서는 상기 두가지 방법을 통 합하여 입체영상의 입체감 향상을 얻을 수 있는 방법을 제 안한다.

그림 3의 블록도에서 보는 것처럼 입력데이터인 RGB 영 상과 깊이맵이 있으면 먼저 깊이맵으로부터 변환 정보를 얻는다. 먼저 이 변환 정보를 RGB 변환에 이용하여, 변환 된 RGB 데이터가 얻어진다. 동시에 이 변환 정보는 새로운 깊이맵을 생성하는데, 활용된다. 최종적으로 $2 \mathrm{D}+\mathrm{Depth}$ 기 법을 이용하여 변환된 RGB 영상과 새로운 깊이맵으로부터
좌우 입체영상을 생성한다. 생성된 입체영상과 입력 RGB 영상과 깊이맵으로부터 얻어진 입체영상과 비교하여 입체 감이 향상된 입체영상을 얻게 된다. 정리하면, 변환 정보는 $\mathrm{RGB}$ 컬러 변환 및 깊이맵 변환에 모두 이용된다.

\section{RGB 컬러 변환}

기본적으로 $2 \mathrm{D}$ 영상의 지각 깊이감을 높이기 위해서 필 요한 변환정보는 깊이맵으로부터 얻어진다. 기본적으로 깊 이맵의 언샤프 마스킹을 활용한다 ${ }^{[1] 10]}$. 이 방법은 신호의 저주파 성분을 제거함으로써, 고주파성분을 얻는 기법중의 하나이다. 예를 들어 언샤프 마스킹은 에지 같은 불연속 영 역에서 보다 민감한 특성을 가지고 있다. 먼저 깊이맵 $\mathrm{D}$ 와 low-pass filter를 통과시킨 $\mathrm{D}$ 의 차이인 $\Delta D$ 는 다음 식 (1) 로부터 구해지며, 변환정보로 이용된다.

$$
\Delta D=G \otimes D-D
$$

여기서 $G \otimes D$ 는 가우시안 필터와 깊이맵의 콘볼류선 (convolution)이다.

실험에서는 1-D 가우시안 커늘을 사용된다. 수평, 수직 으로 1-D 필터를 연속적으로 적용하여 2-D 콘볼류선을 수 행한다. 커늘의 편차 $\sigma=3$ 이면, 필터 계수 $\mathrm{G}$ 는 $[0.1332$

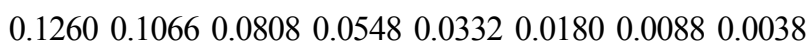
$0.0015]$ 이다. $\sigma=5$ 이면, $\mathrm{G}$ 는 $\left[\begin{array}{lll}0.0801 & 0.07850 .07390 .0669\end{array}\right.$ $\begin{array}{lllllllll}0.0582 & 0.0486 & 0.0390 & 0.0301 & 0.0223 & 0.0158 & 0.0108 & 0.0071\end{array}$

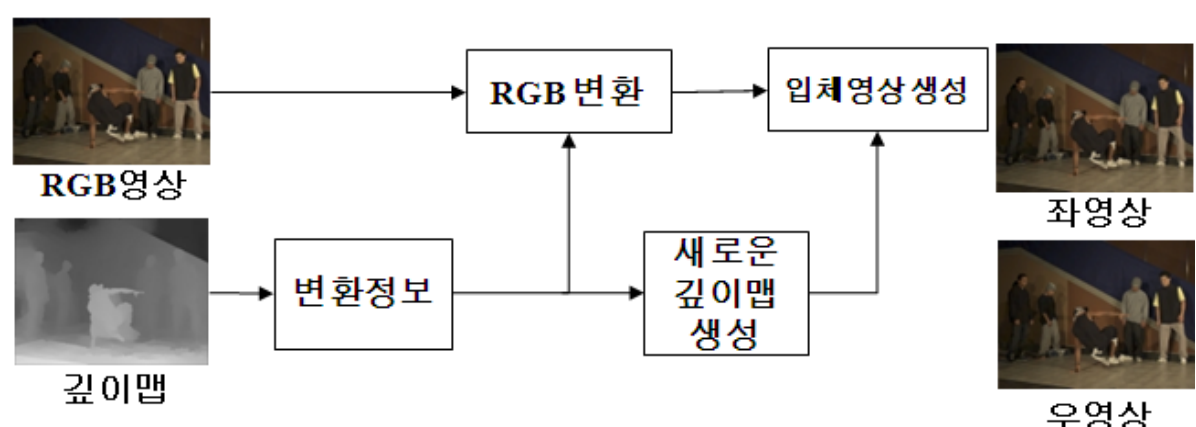

그림 3. 제안 방법의 블록도

Fig. 3. The block diagram of the proposed method 


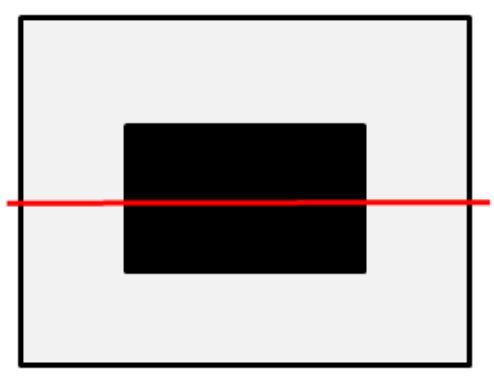

(a)



(b)



(c)

그림 4. 합성 깊이맵에서 얻어진 $\Delta D$. (a) 합성 깊이맵 $\mathrm{D}$, (b) 스캔 라인의 깊이 그래프, 및 (c) $\Delta D$ 의 그래프

Fig. 4. $\Delta \mathrm{D}$ obtained from a synthetic depth map. (a) synthetic depth map $\mathrm{D}$, (b) depth graph along a scanline, and (c) the graph of $\Delta \mathrm{D}$

$0.00450 .00270 .0016]$ 이다.

$\Delta D$ 는 국부(local) 깊이 대조를 의미하는데, $\Delta D$ 는 크기 와 부호에 따라, $|\Delta D| \leq T$ 는 중요하지 않은 영역, $|\Delta D|>T$ 는 관심 영역으로 분류된다. 또한 관심 영역에서 $\Delta D<0$ 는 경계 영역에서 깊이값이 상대적으로 작은 영역 (예: 배경)을, $\Delta D>0$ 는 깊이값이 큰 영역 (예: 전경객체) 을 나타나게 된다. 그림 4는 (a)의 합성(synthetic) 깊이맵이 주어지면, 특정 스캔 라인에서 깊이의 프로화일과 $\Delta D$ 를 보여준다. 깊이의 비연속이 발생할 때에 (예: 에지), $\Delta D$ 는 음에서 양으로, 또는 양에서 음으로 부호(sign)가 변경되는 것을 알 수 있다.

다음은 $\Delta D$ 에 기반한 영상 처리 기법이다. 먼저 $\Delta D$ 의 범위를 $[0,1]$ 로 하여 정규화된 $\Delta D_{N}$ 을 구한다. 다음 2 가지 는 $\Delta D_{N}$ 을 활용하는 방법이다.

\section{1. 대조 변환 (Contrast transformation)}

에지에 관련된 공간 정보를 포함하는 $\Delta D$ 는 입력 영상 $\mathrm{I}(\mathrm{I} \in\{\mathrm{R}, \mathrm{G}, \mathrm{B}\})$ 에 식 (2)처럼 더하여 새로운 영상 $\mathrm{R}^{\prime} \mathrm{G}^{\prime} \mathrm{B}^{\prime}$ 을 얻는다.

$$
\begin{aligned}
& R^{\prime}=R+\lambda \cdot\left(\Delta D_{N}\right) \\
& G^{\prime}=G+\lambda \cdot\left(\Delta D_{N}\right) \\
& B^{\prime}=B+\lambda \cdot\left(\Delta D_{N}\right)
\end{aligned}
$$

여기서 $\lambda$ 는 실수이며 사용자가 정하는 가중치이다. 부호
에 따라 $\mathrm{RGB}$ 값이 증감한다.

\section{2. 배경 다크닝 (Background darkening)}

이 방법은 상대적으로 깊이가 작은 배경영역을 어둡게 함으로써 지각 깊이 화질을 높인다. 객체와 배경의 컬러 차 이가 별로 없는 영상에 적용할 수 있는 방법으로 에지 부근 에서 배경 영역을 어둡게 하는 것이다. 다음과 같이 계산한 다.

$$
\begin{aligned}
& R^{\prime}=R+\lambda \cdot \Delta D_{N}^{-} \\
& G^{\prime}=G+\lambda \cdot \Delta D_{N}^{-} \\
& B^{\prime}=B+\lambda \cdot \Delta D_{N}^{-}
\end{aligned}
$$

여기서 $\Delta D_{N}^{-}$는 $\Delta D_{N}$ 의 음수값이다. $\lambda>0$ 로 양수값을 가진다.

상기 기법들을 합성 영상 및 깊이맵에 적용하여 결과를 조사하였다. 결과영상은 그림 5에서 보여준다. 그림 5(a)는 합성 영상, (b)는 (a)의 깊이맵이다. 영상내의 객체들과 깊 이는 다양하게 분포하도록 하였다. (c)는 대조 변환을 적용 한 결과이고, $\lambda>0$ 이다. (d)는 $\lambda<0$ 이다. (e)는 배경 다 크닝을 적용한 결과이다. 깊이 불연속 영역에서 픽셀 값이 깊이의 분포에 따라 변화되는 것을 관찰할 수 있다. 또한 (c), (d), (e)를 (a)와 비교해서 관찰하면, 영상의 지각 깊이 감이 향상되는 것을 알 수 있다. 그러나 부분적으로 에지에 서 화질의 저하가 관찰되지만, 깊이감의 측면에서 판단하 


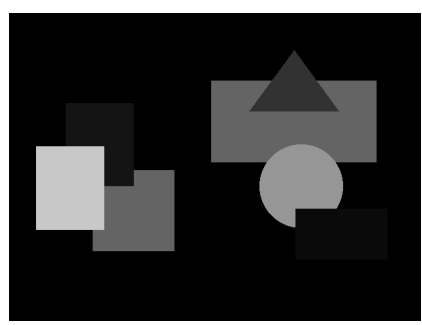

(a)

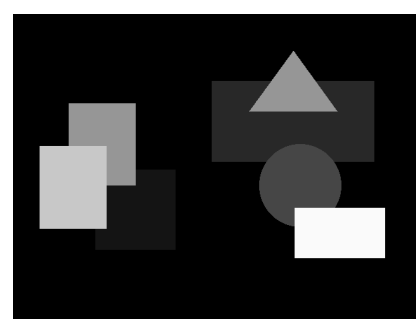

(b)



(c)

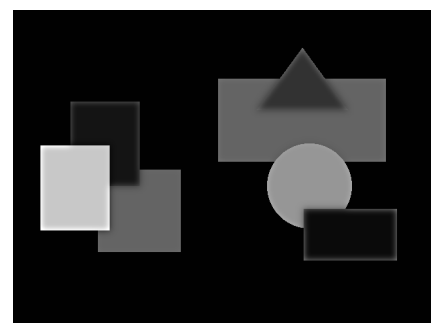

(d)

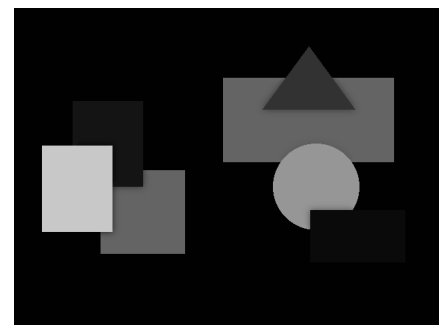

(e)

그림 5. 제안기법의 결과. (a) 입력 영상, (b) 깊이맵, (c) 대조 변환 $(\lambda>0)$, (d) 대조 변환 $(\lambda<0)$, 및 (e) 배경 다크닝 $(\lambda>0)$

Fig. 5. Resulting images of the proposed method. (a) input image, (b) depth map, (c) contrast transformation $(\lambda>0)$, (d) contrast transformation $(\lambda<0)$, and $(e)$ background darkening $(\lambda>0)$

면 원영상과 비교하여 깊이감이 증가한다. 수행한 주관실 험의 평가에서 화질 저하가 입체감의 평가에 어느정도 영 향을 주는 것이 관찰된다.

\section{IV. 깊이맵 변환}

기존의 깊이맵 변환 연구는 $3 \mathrm{D}$ 장면과 유사한 입체영상 을 만들기 위해 비선형 변환을 사용하기도 하고, 객체를 분 리해서 좀더 사실적인 입체영상을 만들기 위하여 깊이맵을 재조정하기도 한다 ${ }^{[6-9]}$. Felderman 등이 제안한 방식은 깊 이와 픽셀 변이와의 관계를 분석한 후에 비선형 깊이를 얻 는담․ 또한 Redker 등은 3D 디스플레이 특성에 맞게 깊이 맵을 변환한 후에, 이 변환된 깊이맵을 이용하여, 좌우 입체 영상을 생성하였다 ${ }^{[7]}$. 제안 방법은 [7]에서 제안한 방법에 기반을 하는데, 3 장에서 얻은 변환 정보 $\Delta D$ 를 다시 활용하 여, RGB 컬러 변환과 일치하도록 한다. 식 (1)과 같이 깊이 맵 $\mathrm{D}$ 에 가우시안 저주파 필터 $\mathrm{G}$ 를 적용하여 $\Delta D$ 를 구한다.

$$
\Delta D=D-G \otimes D
$$

구해진 $\Delta D$ 의 범위는 [-Dmax, $+\mathrm{Dmax}]$ 에 있다고 가정 한다. $\Delta D$ 는 그림 4(c)와 같이 에지 픽셀에서 큰 변화가 발 생한다. $\Delta D$ 의 절대값 $|\Delta D|$ 에 저주파 필터를 적용하면, 저 주파 신호 $\mathrm{De}$ 을 얻을 수 있는데, 다음 식으로 이용하여 표 현된다.

$$
\mathrm{De}=\tau \cdot \mathrm{G}(|\Delta D|)
$$

여기서 $\tau$ 는 사용자가 지정하는 가중치로, De의 크기를 조절한다. $\mathrm{G}$ 는 가우시안 필터이다.

다음 식 (6)를 이용하여, DS를 구한다.

$$
D_{S}=D_{\max } \frac{\Delta D}{D_{e}}
$$

$\mathrm{De}$ 는 깊이맵 변환에서 중요한 역할을 한다. 즉, 에지에서 의 깊이의 변화율에 관계없이 주변 픽셀들의 컬러값이 일 정한 비율로 증가 또는 감소하도록 한다. 마지막으로, 입체 영상 생성에서 사용되는 최종 깊이맵 $\mathrm{DF}$ 는 D에 $\mathrm{DS}$ 을 합하 여 구해진다. 


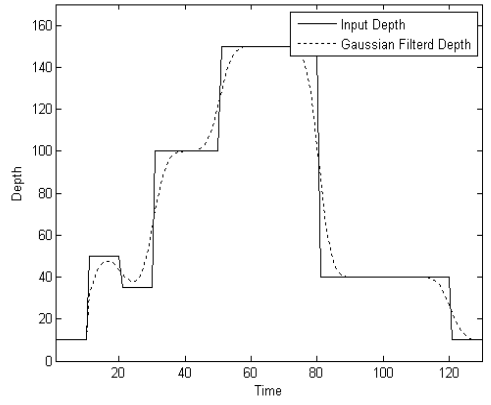

(a)

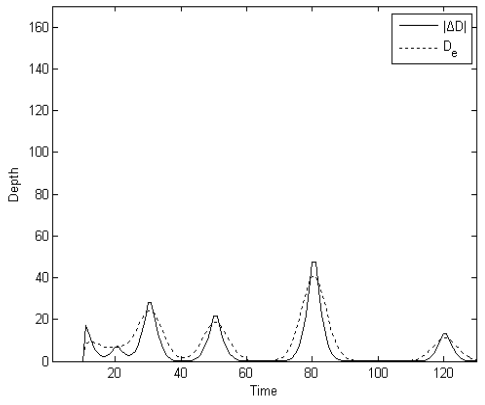

(b)

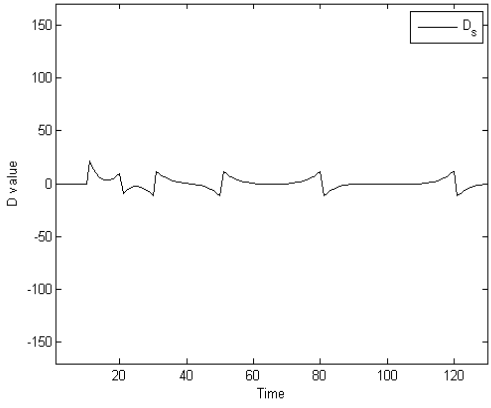

(c)

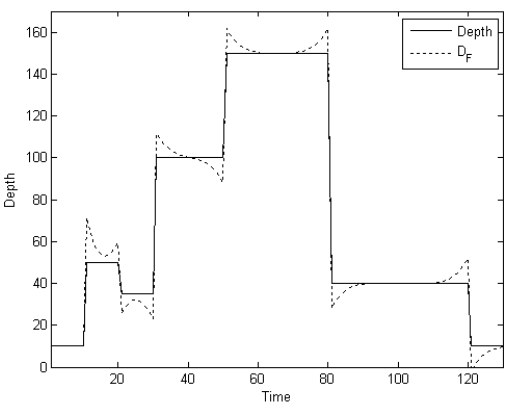

(d)

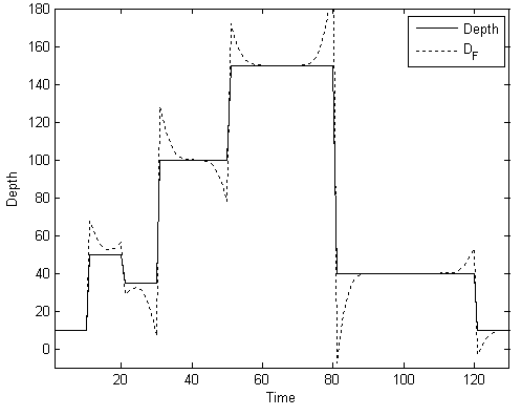

(e)

그림 6. 신호의 그래프. (a) 입력 및 가우시안 필터링된 신호, (b) $|\Delta D|$ 와 $\mathrm{De}$, (c) Ds, (d) 입력 깊이와 출력 깊이, 및 (2) De를 사용하지 않은 출력 깊이 Fig. 6. The graph of signals. (a) input and gaussian-filtered signals, (b) $|\Delta D|$ and $\mathrm{De}$, (c) Ds, (d) input and output depths, and (2) output depth without using $\mathrm{De}$

$$
D_{F}=D+D_{S}
$$

그림 6의 그래프는 상기 깊이맵 변환 과정을 보여준다. (a)는 스캔라인에서의 깊이와 필터링된 깊이 프로화일의 그래프를 보여준다. (b)는 $|\Delta D|$ 와 식 (5)의 $\mathrm{De}$ 을 보여준 다. (c)의 그래프는 식 (6)의 Ds를 보여주는데, $\mathrm{D}$ 의 크기 에 관계없이 일정한 비율로 증감되는 것을 확인할 수 있 다. 이 효과를 분석하기 위하여 그래프 (d)와 (e)는 De를 사용했을 때와 사용하지 않은 최종 깊이맵 $\mathrm{DF}$ 를 보여준 다. (e)에서 관찰하듯이 $\mathrm{De}$ 을 사용하지 않으면 에지에서 깊이 변화가 불규칙한 것을 알 수 있다. 예를 들어 동일 선(line)에 있는 에지 픽셀에서의 깊이값 변화가 달라지 게 되므로, 입체영상으로 보게 되면 입체감의 저하가 발 생하게 된다.

마지막으로 2D 영상과 깊이맵이 주어지면 식 (8)과 (9)
를 이용하여 픽셀의 변이(disparity)를 구해 영상을 좌측 및 우측으로 수평으로 이동하여 각각 좌영상과 우영상을 만 든다.

$$
\begin{aligned}
& I_{L}(x-d, y)=I(x, y) \\
& I_{R}(x+d, y)=I(x, y)
\end{aligned}
$$

여기서 IL과 IR은 각각 좌·우 영상이고, 변이 d는 다음 식을 이용하여 깊이 $\mathrm{DF}$ 로부터 계산한다.

$$
d=\rho \times\left(1.0-\frac{D_{F}}{255}\right)
$$

여기서 $\rho$ 는 최대시차 값이고, 실험에서 사용한 값은 10 (픽셀)이었다. 


\section{V. 실험 결과}

실험에서 사용한 영상으로 그림 7의 MSR의 Break-
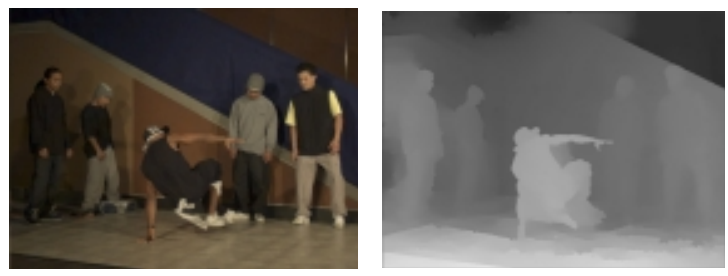

(a)


(b)


(c)

그림 7. 실험영상 및 깊이맵. (a) MSR Breakdancer, (b) HHI Interview, 및 (c) Middlebury의 Wood2

Fig. 7. Test images and depth maps. (a) MSR Breakdancer, (b) HHI Interview, and (c) Middlebury Wood2 dancer ${ }^{[11]}, \mathrm{HHI}$ 의 Interview, 및 Middelbury의 $\operatorname{Wood} 2^{[12]}$ 의 $\mathrm{RGB}$ 영상과 깊이맵을 사용하였다. 실험영상들은 일반적 으로 $2 \mathrm{D}+\mathrm{Depth}$ 에서 사용되는 영상이다. 시각적 피로도 없 이 제작된 입체영상을 시청할 수 있다.

그림 8 은 $\Delta D$ 의 부호로 분류한 픽셀의 분포를 보여주는 영상이다. 에지 픽셀을 중심으로 객체의 전경 영역은 blue 로 표시되고, 배경 영역은 red로 표시되었다. $|\Delta D|$ 의 임계 값 $\mathrm{T}$ 는 2.0 이다.

그림 9(a)와 (b)는 입력 깊이맵과 최종 변환된 깊이맵을 보여준다. 그림 9의 (c), (d), (e)의 그래프는 (a)의 $\mathrm{y}=230$ 에 서 깊이 값의 프로화일, $\mathrm{DS}$, 및 $\mathrm{DF}$ 를 보여준다. 깊이맵 $\mathrm{D}$ 의 정확도가 낮기 때문에, 두 전경 객체의 에지 영역에서 $\mathrm{DS}$ 의 변화가 약간 불규칙한 것을 관찰할 수 있다. 객체 내 부에서 심한 불규칙이 발생하는데, 스테레오 매칭 등으로 얻어진 실사영상의 깊이맵은 노이즈 등으로 정확성이 낮다. 그러나, 부드러운 영역에서는 깊이값이 차이, 즉 $\Delta D$ 가 작 다. 따라서, $\mathrm{RGB}$ 값의 변화가 상대적으로 적기 때문에 큰 영향은 없다.

3장에서 제안한 지각 깊이 화질 개선 방법 중 대조 변환에서 얻은 입체영상은 그림 10 에서 보여준다. 결과 영상을 보면 전경 객체의 에지 주변에서 전경 영역은 밝게, 배경 영역은 어둡게 되는 등의 대조 변화가 발생 하다. 그림 10 의 (c), (d), (e)의 그래프는 Interview 영상의 한 스캔라인에서 좌우영상의 Red 성분의 변화 차이를 보여준다.
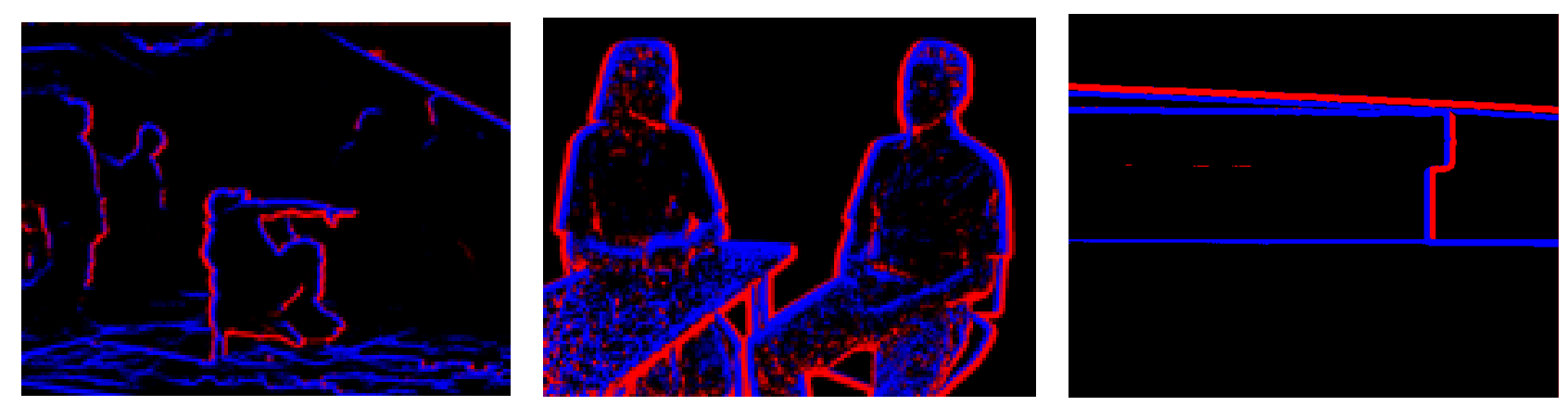

그림 8. $\Delta D$ 의 부호로 분류한 픽셀. $\Delta D>0$ (blue), $\Delta D<0$ (red), 및 $|\Delta D|<T$ (black)

Fig. 8. Pixels classified by the sign of $\Delta D$. $\Delta \mathrm{D}>0$ (blue), $\Delta \mathrm{D}<0$ (red), and $\Delta \mathrm{D} \mid<\mathrm{T}$ (black) 

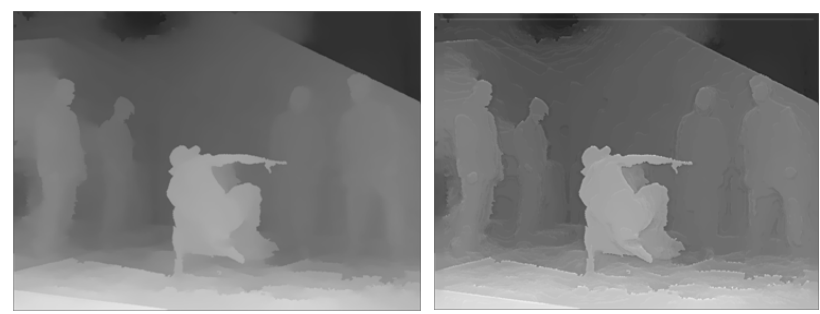

(a)

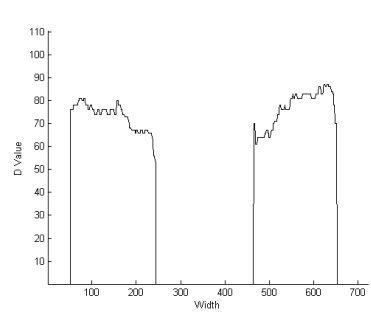

(c)
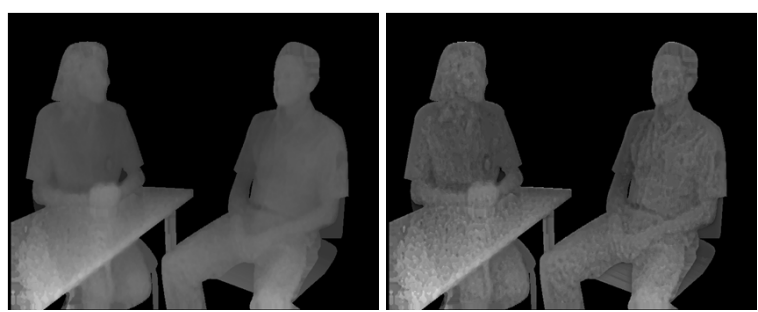

(b)

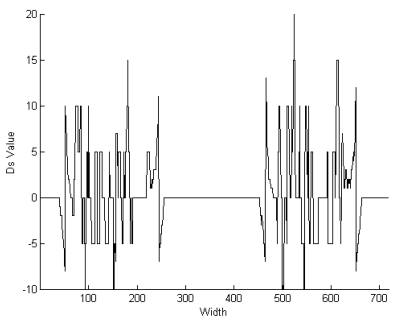

(d)

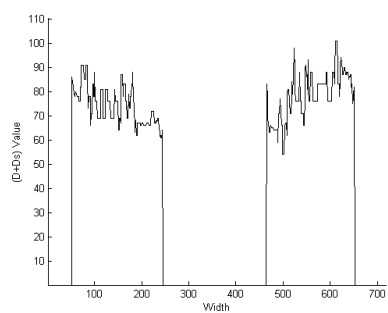

(e)

그림 9. (a) 입력 깊이맵, (b) 변환된 깊이맵, (c) D, (d) DS 및 (e) DF

Fig. 9. (a) input depth map, (b) transformed depth map, (c) D, (d) DS and (e) DF

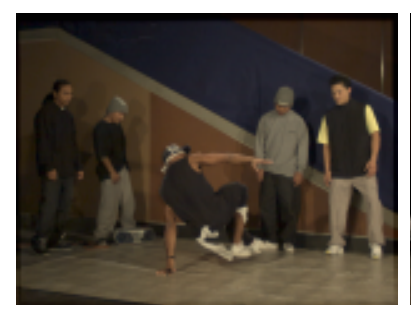

(a)

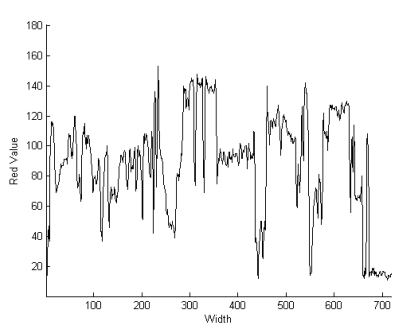

(c)
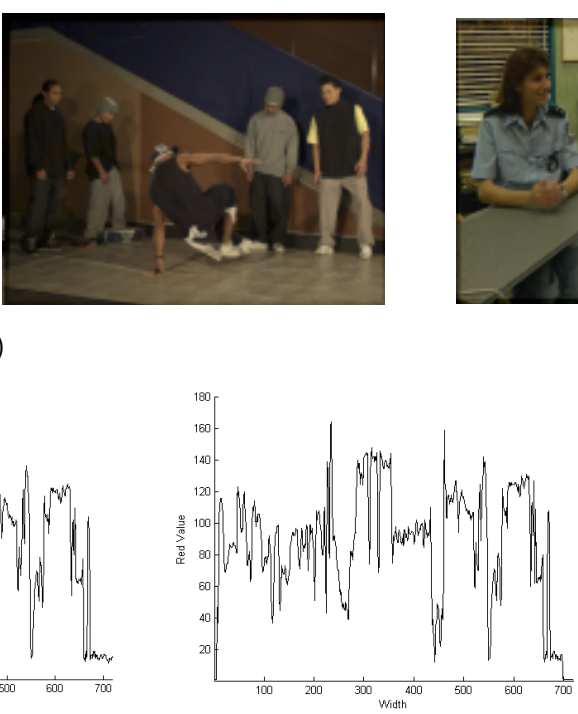

(d)
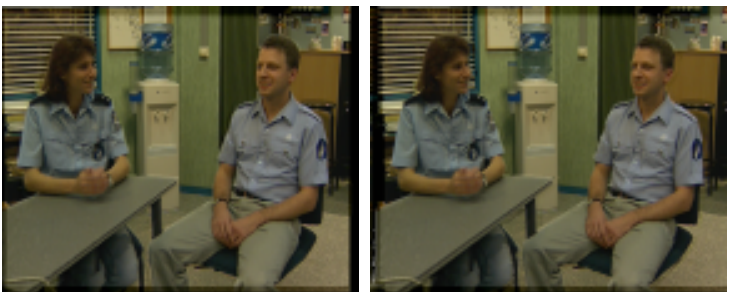

(b)

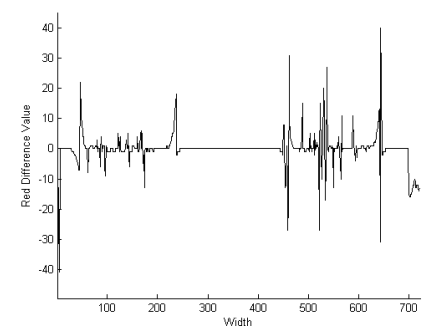

(e)

그림 10. 대조 변환을 적용한 입체영상. (a) 좌영상, (b) 우영상, (c) 영상의 Red 성분, (d) 좌영상의 Red 성분, (e) (c)와 (d)의 차이값

Fig. 10. Stereoscopic images obtained from the contrast transformation. (a) left image and (b) right image, (c) Red component of the left image, (d) Red component of the right image, and (e) the difference signal of (c) and (d).

배경 다크닝에서 얻은 입체영상은 그림 11에서 보여준 다. 결과 영상을 보면 전경 객체의 에지 주변에서 배경 영역
만 어둡게 변화된다. 그림 11 의 (c), (d), (e)의 그래프는 Interview 영상의 한 스캔라인에서 좌우영상의 Red 성분의 

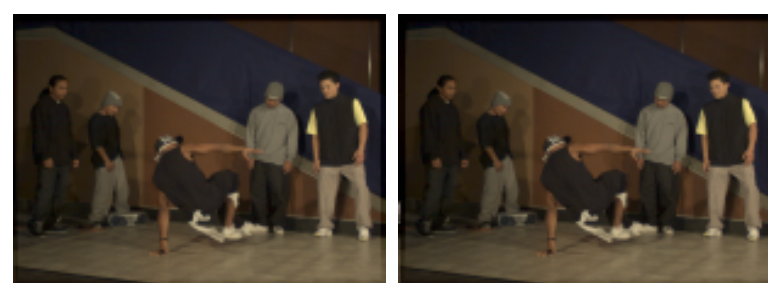

(a)
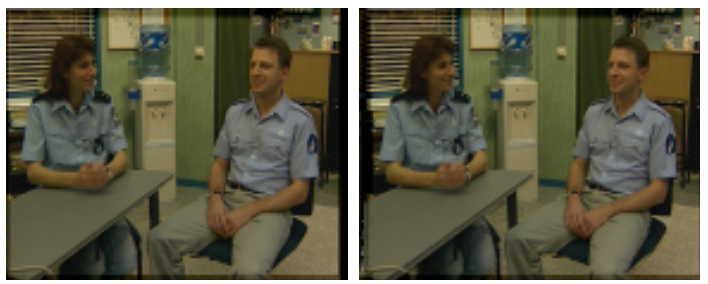

(b)
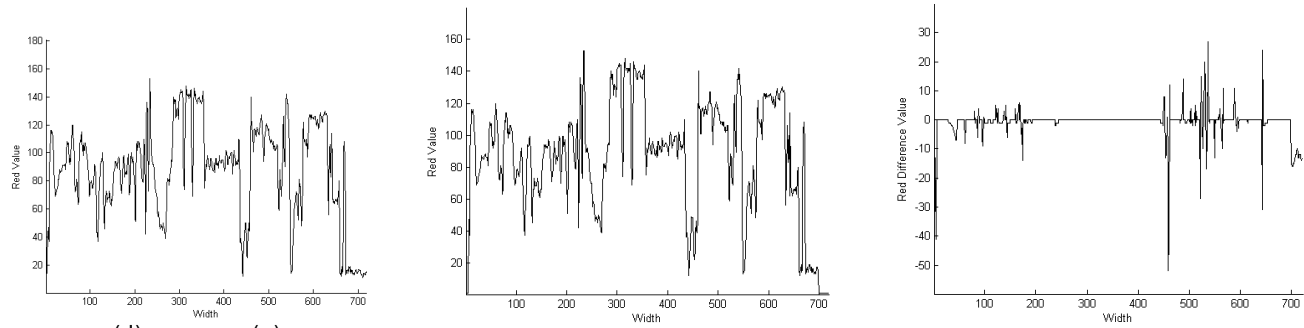

(c)

(d)

(e)

그림 11. 배경 다크닝을 적용한 입체영상. (a) 좌영상, (b) 우영상, (c) 원영상의 Red 성분, (d) 좌영상의 Red 성분, (e) (c)와 (d)의 차이

Fig. 11. Stereoscopic images obtained from the background darkening. (a) left image and (b) right image, (c) red component of the left image, (d) red component of the right image, and (e) the difference of (c) and (d).

변화 차이를 보여준다.

그림 12 는 그림 10 의 댄서의 우측 팔의 확대 영상을 보여

(a)

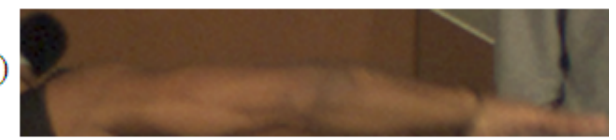

(b)

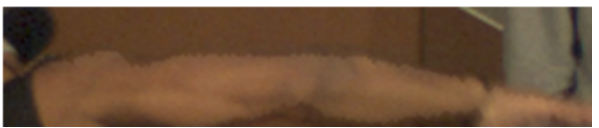

그림 12. 그림 10 (a) Breakdancer의 확대영상. (a) 원영상, (b) 대조 변환 영상 Fig. 12. Close-up of Fig. 10 (a) Breakdancer. (a) original image and (b) contrast-transformed image
준다. 팔의 위쪽 경계 부근에서 깊이값에 따라 RGB 값이 증가 또는 감소되는 것을 알 수 있다. 이러한 대조 변화는 입체영상의 주관적 실험에서 입체감을 향상시키는 효과를 준다.

그림 13은 Middlebury 실험영상인 Wood2에 제안 방법 을 적용한 결과영상이다. 그림 13 (a)의 깊이맵을 관찰하면 상단에서 깊이값이 차이가 큰 것을 알 수 있다. 따라서, (c) 의 영상을 보면, 상단 부분에서 컬러의 변화가 큰 것을 알 수 있다. 마찬가지로 컬러의 변화는 실제 입체영상으로 시 청했을 때 입체감을 증가시키는 효과가 있다. 그림 14 는 그



(a)

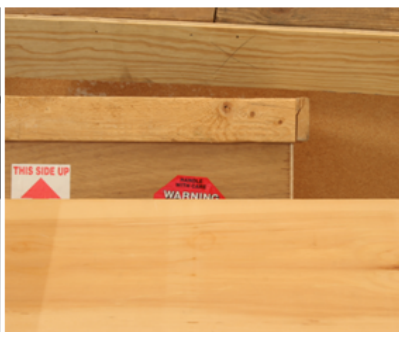

(b)

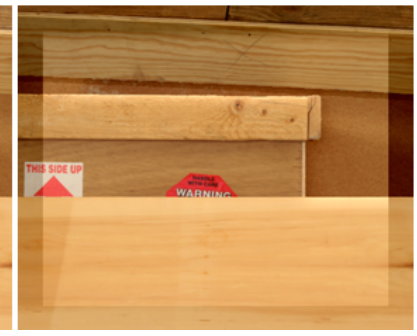

(c)

그림 13. Middelbury Wood2 영상. (a) 깊이맵, (b) 원영상, 및 (c) 대조 변환 영상

Fig. 13. Middelbury Wood2 image. (a) depth map, (b) original image, and (c) contrast-transformed image 
림 13 의 (a), (b)의 확대영상이다.

(a)

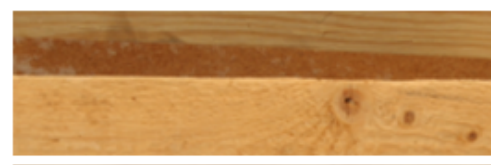

(b)

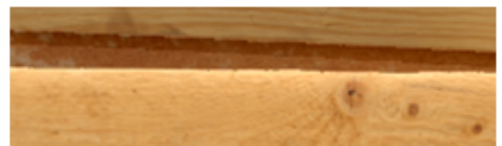

그림 14. 그림 13 (b), (c) 의 확대영상. (a) 원영상, (b) 대조 변환 영상 Fig. 14. Close-up of Fig. 13 (b) and (c). b) original image and (c) contrast-transformed image

실험에서는 원영상과 깊이맵으로 만든 Breakdancer, Interview 및 Wood2의 입체영상과 제안 방법인 대조 변환 및 배경 다크닝에서 얻은 입체영상을 비교 검증하였다. 입 체영상들을 3D 2-시점 입체 모니터로 시청하여 인식되는 깊이 지각 화질의 차이를 비교하였다. 주관적 평가를 위해, DSCQS (Double Stimulus Continuous Quality Scale) 실험 을 실행하였다 ${ }^{[13]}$. 첫 단계에서는 5 장의 원영상을 5 명의 실 험자에게 보여주었고, 각 실험자는 각각 10 초 동안 원 입체 영상과 출력 입체 영상들을 관측하였다. $\lambda$ 의 범위는 $[5,30]$ 이다. 입체감은 다음의 1 5의 값에서 주관적으로 평가하였 다: 전혀 입체향상이 없음 (1점), 입체향상이 조금 있음 (2 점), 입체향상이 중간정도임 (3점), 입체향상이 좋음 (4점), 입체향상이 매우 좋음 (5점). 주관평가의 결과는 그림 15 에 서 보여진다. 수직축의 $1 \sim 5$ 는 평가 점수이고, $\lambda$ 는 수평축에
표시된다. 실험자에게는 실험 전에 화질 평가가 아닌, 입체 감 평가가 주 목적임을 알려주었다. 또한 화질의 저하에 따 른 피로도 측정은 평가에 포함되지 않음을 설명해주었다. 그래프에서 보듯이, 평가 점수는 $\lambda$ 에 비례하고 있고, $\lambda$ 가 5 인 경우에도 평가점수는 2 (조금 향상)에 근접한다. $\lambda$ 가 증가하면 비례적으로 평가점수가 증가함으로써, 제안방법 이 입체 지각화질 개선에 도움이 된다는 것을 알 수 있다. 입체감 향상은 Interview, Breakdancer, Wood2의 순서로 되어 있는데, 그 이유는 깊이맵의 정확성에 1 차 원인을 찾 을 수 있다. HHI의 깊이맵은 신뢰성이 상대적으로 낮고, Wood2가 가장 깊이맵의 정확도가 높다. 가 크게 증가하 면, RGB 컬러의 색 저하 현상이 발생할 수도 있지만, 입체 감에는 큰 영향을 주지 않음을 알 수 있다. 그러나 $\lambda$ 가 증가 하면 컬러 화질의 저하가 발생하는 단점이 있다. 컬러의 지 나친 변화는 입체영상 시청시의 컬러의 왜곡이 발생한다. 따라서, 입체영상을 시청할 때에 시각적 피로의 원인이 된 다. 대조변환이 상대적으로 배경 다크닝보다 평가점수가 높은데, 에지 주변의 두 영역의 RGB를 변환하는 것이 더 효과가 있음을 보여준다.

상기 주관적 실험에서는 시각적 피로도와 무관하게 입체 감 향상에 실험의 목적을 맞추었다. 두 번째 실험에서는 실 험결과에서 관찰되듯이 $\lambda$ 가 증가하면 화질의 열화가 발생 하게 된다. 이에 따라 영상을 시청한 후에 느껴지는 피로도 에 대해서 1(피로함)부터 5(편안함)까지의 점수를 주는 방 식으로 평가를 진행하였다 ${ }^{[14-16]}$. 점수는 다음과 같다: 매

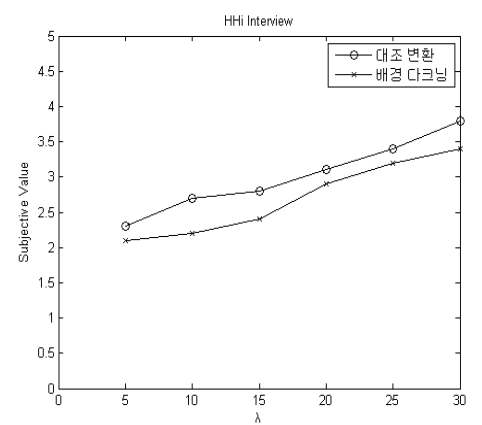

(a)

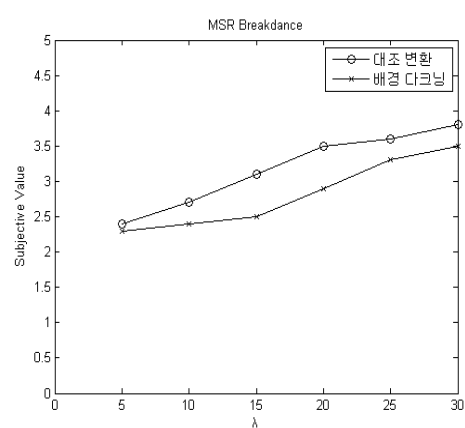

(b)



(c)

그림 15. 실험 영상의 $\lambda$ 와 주관적 입체감 평가 점수의 관계. (a) Interview, (b) Breakdancer, 및 (c) Wood2

Fig. 15. Relation between $\lambda$ and subjective stereoscopic-perception evaluation grade for test images. (a) Interview, (b) Breakdancer, and (c) Wood2 

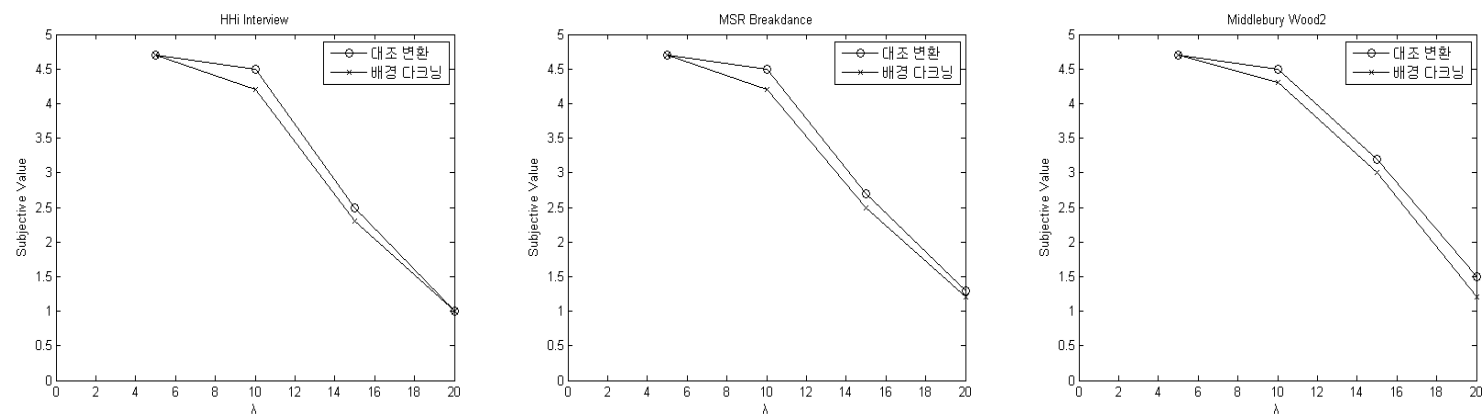

그림 16. 실험 영상의 $\lambda$ 와 주관적 피로도 평가 점수의 관계. (a) Interview, (b) Breakdancer, 및 (c) Wood2

Fig. 16. Relation between $\lambda$ and subjective fatigue evaluation grade for test images. (a) Interview, (b) Breakdancer, and (c) Wood2

우 (severe) 피로함 (1점), 피로함 (2점), 좀 (moderate) 피로 함 (3점), 약간 (slight) 피로함 (4점), 전혀 피로함 없음 (5 점). 평가 순서는 입체감 향상 평가와 유사하게 진행되었다. 그림 16 은 주관적 피로도의 결과를 보여준다. 시각적 피로 도는 $N$ 가 증가하면서 화질의 열화가 증가하므로, 이에 따라 피로도가 증가하는 것을 알 수 있다. $\lambda$ 값이 10 보다 커지면 피로도가 급격히 증가하는데, 이 현상은 입체감과 피로도 를 동시에 만족하는 최적 입체영상의 생성에 주요 요인이 된다.

\section{VI. 결론 및 향후 연구}

본 논문에서는 기존의 $2 \mathrm{D}$ 영상의 컬러 변환을 통한 지각 깊이감 향상 기법을 $3 \mathrm{D}$ 입체영상으로 확장하여 입체영상 의 $3 \mathrm{D}$ 지각 입체감의 개선 방법을 제안하였다. 이를 위해서 대조 변환과 배경 다크닝 기법을 입체영상 개선에 적용하 였다. 깊이맵으로부터 얻은 변환 정보를 컬러 및 깊이에 동 시에 적용하여 컬러 및 깊이맵 변환의 동질성을 유지하였 고, 원 입체영상보다 입체감이 개선되는 것을 주관적 실험 을 통하여 증명하였다. 또한 피로도 측정에서는 $\lambda$ 값이 특정 임계치보다 커지면 피로도가 증가하는 것을 보여주었다. 따라서 입체감과 피로도를 동시에 만족하는 최적 입체영상 의 구현이 필요하다. 제안 방법은 입체영상 분야에 새로운 기술을 제시함과 동시에 향후 입체영상의 입체감 개선 기 술에 기여할 것으로 기대한다.

\section{참 고 문 헌}

[1] T. Luft, C. Colditz, and O. Deussen, "Image enhancement by unsharp masking the depth buffer," In Proceedings of ACM SIGGRAPH, pp. 1206-1213, 2006.

[2] N. A. Svakhine, D. S. Ebert, and W. M. Andrews, "Illustration-inspired depth enhanced volumetric medical visualization," IEEE Trans. on Visualization and Computer Graphics, Vol. 15, No. 1, Jan/Feb. 2009.

[3] S. Bruckner and M. E. Groller, "Enhancing depth- perception with flexible volumetric halos," IEEE Trans. on Visualization and Computer Graphics, Vol. 13, Issue 6, pp 1344-1351. Nov. 2007.

[4] 정길수, 강민성, 김동현, 손광훈, “색상 보정을 통한 3 차원 TV의 입체영상 화질 개선”, 방송공학회논문지, 제 15 권 제 6호, pp. 757-767, 2010년 11 월.

[5] 조철용, 김만배, 엄기문, 허남호, 김진웅, “변이기반 다시점 영상의 인식 깊 이감 조절”, 방송공학회논문지 제 13 권 제 6호, pp. 796-803, 2008년 11월.

[6] I. Feldmann, O. Schreer, and P. Kauff, "Nonlinear Depth Scaling for Immersive Video Applications," Proceedings of WIAMIS 2003, April 9-11, 2003.

[7] A. Redert, "Visualization of arbitrary-shaped 3D scenes on depth-limited 3D displays," In Proceedings of 3DPVT, pp. 938-942, 2004.

[8] G. Jones, D. Lee, N. Holliman, and D. Ezra, "Controlling Perceived Depth in Stereoscopic Images," Stereoscopic Displays and Virtual Systems VIII, Proceedings of SPIE Vol. 4297, pp. 42-53, 2001.

[9] L. Stelmach, W. Tam, F. Speranza, R. Renaud, and T. Martin, "Improving the Visual Discomfort of Stereoscopic Images," Stereoscopic Displays and Virtual Systems X, Proceedings of SPIE-IS\&T Electronic Imaging, SPIE Vol. 5006, pp. 269-282, 2003.

[10] Gonzales, Digital Image Processing, PrenticeHall, 2001.

[11] http://research.microsoft.com/vision/Interactive VisualMediaGroup/3DVideoDownload/, Microsoft Research

[12] http://vision.middlebury.edu/stereo/

[13] "Subjective assessment of stereoscopic television picutre," ITU-R Recommendation BT. 1438, 2000.

[14] 이형철, “주관적인 3차원 피로감 측정 방법에 대한 휴먼 팩터 연구”, 방송 공학회논문지 제 15 권 제 5호, pp. 607-616, 2010년 9월.

[15] 김동현, 최성환, 손광훈, “시청자의 입체시 특성을 고려한 $3 \mathrm{D}$ 비디오의 피 
로도 예측”, 방송공학회논문지 제 16권 제 2호, pp. 331-338, 2011년 3월. [16] J. Choi, D. Kim, B. Ham, S. Choi, K. Sohn, "Visual fatigue evaluation and enhancement for 2D-plus-depth video," International Conference on Image Processing, pp. 2981-2984, 2010.

저 자 소 개
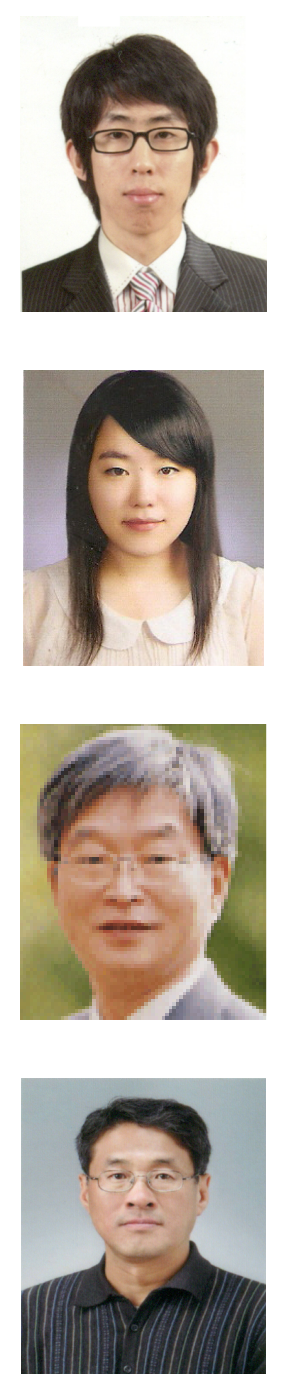

\section{길 종 인}

- 2010년 8월 : 강원대학교 컴퓨터정보통신공학과 학사

- 2010년 9월 현재 : 강원대학교 컴퓨터정보통신공학과 석사과정

- 주관심분야 : 3D영상처리, 컴퓨터그래픽스, 홀로그램

\section{장 성 은}

- 2011년 2월 : 강원대학교 컴퓨터정보통신공학과 학사

- 2011년 3월 현재 : 강원대학교 컴퓨터정보통신공학과 석사과정

- 주관심분야 : 입체영상처리, $3 \mathrm{D}$ 모바일, 입체변환

\section{서 주 하}

- 1977년 : 서울대학교 전기공학 학사

- 1979년 : 서울대학교 전기공학 석사

- 1985년 : 프랑스 낭트대 전기공학 박사

- 1986년 현재 : 강원대학교 컴퓨터정보통신공학과 교수

- 주관심분야 : 3D전송, 멀티디미어통신

\section{김 만 배}

- 1983년 : 한양대학교 전지공학과 학사

- 1986년 : University of Washington 전기공학과 공학석사

- 1992년 : University of Washington 전기공학과 공학박사

- 1992년 1998년 : 삼성종합기술원 수석연구원

- 1998년 현재 : 강원대학교 컴퓨터정보통신공학과 교수

- 주관심분야 : 3D영상처리, 홀로그램데이터처리, 입체변환 